\title{
New educational technologies in the educational and professional motivation of undergraduate students in the field of ecology
}

\author{
Olga Shefer ${ }^{1, *}$, Svetlana Kraineva $^{2}$, and Tatyana Lebedeva ${ }^{1}$ \\ ${ }^{1}$ South Ural State Humanitarian Pedagogical University, 454080, Chelyabinsk, Russia \\ ${ }^{2}$ Ural State University of Railway Transport, 66, Kolmogorova-str., 620034, Ekaterinburg, Russia
}

\begin{abstract}
The article presents a study of the influence of the specifics of the formation of the motivational sphere of undergraduate students on their readiness and ability to perform their labor functions for obtaining a quality education. High-quality education is the basis for a decent life and sustainable personal and social development, which contributes to changing the labor market in all countries of the world, blurring the boundaries between the physical, digital, and psychological and biological spheres. The study of this topic is extremely important for Russia, which seeks to overcome the negative consequences on the labor market and lag behind global trends in development through the implementation of the strategy 2016-2030. As a result of the work, a cluster of pedagogical technologies "UnInd of motivations" was created, which has wide opportunities and allows to implement the educational process in a new way in the modern conditions of the university, namely: to create conditions for improving the training of a university student, increasing the motivation of learning by solving case problems of a practice-oriented nature, to create conditions for further self-improvement in the professional sphere.
\end{abstract}

\section{Introduction}

In modern rapidly changing world, the education system must be able to correspond to numerous challenges of the present-day reality. The Sustainable Development Goals are a kind of call to action from all countries. The goal, related to quality education - is the foundation for a decent life and is proclaimed by the UN as the Sustainable Development Goal for the period up to 2030 .

Education provides the foundation for improving people's socio-economic conditions and plays a key role in lifting them out of poverty. Quality education will combine digital, physical, and biological systems [1].

The consequences of the labor market change are disappearance of some professions and appearance of completely new ones based on the SMART-technologies. Therefore, in addition to information and computer competence, the basic skills for professionals of the future will be ability to activate critical thinking, develop partnerships, active use SMART-

${ }^{*}$ Corresponding author: shefer-olga@yandex.ru 
technologies for effectively processing huge amounts of information, master innovations in the professional sphere quickly and purposefully [2;3].

In practice, according to M. Bogorodskaya and V. P. Chemekov, the training of the younger generation in the era of implementing the Sustainable Development Goals will not be limited to a specific specialty. In addition, a career of the younger generation will necessarily be associated with adapting to emerging challenges, as well as with continuous development taking into account grading [4; 5].

In the interests of education and upbringing of the younger generation, expanding access to education and increasing school enrolment, the factors that form the values of educational and professional-motivational choice are investigated [6;7]. Modern teachers of mathematics and natural sciences improve their qualifications on a large scale [8].

To protect the well-being of children and ensure their access to lifelong learning, in March 2020, UNESCO launched the Global Coalition on Education for COVID-19, a multisectoral partnership between UN agencies, civil society organizations, the media and IT partners to develop and implement innovative solutions. Together, they help countries address gaps in content and connectivity, and create opportunities for inclusive learning for children and young people during this period of sudden and unprecedented disruption to the educational process. In particular, the Global Education Coalition aims to: assist countries in mobilizing and implementing innovative and situation-specific solutions for distance learning, using high-tech, low-tech, and non-technological approaches.

Therefore, distance education methods are being actively introduced, taking into account the personification of learning. A variety of information and communication technologies, specific features of distance and on-line learning are used, which are able to optimize the educational process for achieving the Sustainable Development Goals.

One of the ideas of the Information Society is the so-called "education through all life". Realization of the idea led to the discussions in the scientific and pedagogical literature. Namely, there are discussions of the problems on the development of educational and professional motivation among undergraduate students and the formation of their professional and personal qualities, which are basis of increase in the education of future specialists ready for the achieving the Sustainable Development Goals by means of SMARTtechnologies $[9 ; 10 ; 11 ; 12 ; 13 ; 14]$. In achieving the sustainable Development Goals, one of the most promising innovative areas is the development of SMART-technologies for individualizing education based on the introduction of cloud technologies. Network technologies allow to create an educational environment, which ensure the following three possibilities: successful self-realization of the personality of the young generation for effective social and professional affirmation, quality continuous education, formation of a successful competitive person with developed educational and professional motivation.

\section{Materials and methods}

The most pressing problems in achieving the Sustainable Development Goals are presented in different ways within the framework of various national educational systems taking into account long-term strategies for socio-economic development. On the one hand, the achievement of the Sustainable Development Goals is possible by the implementation of individual trajectories that determine the system of interaction between students from all educational levels and other participants of the educational process within the educational institutions and beyond. Our studies [15] and publications of recent years [16; 17] confirm this fact. On the other hand, there is a real transition from the knowledge to the actionoriented and practice-oriented approach. The solution to this problem is connected with not only the content, but also with the technological aspects of the educational process. One of the most important technological aspects is the technology to form competencies of students. 
According to the society requirements, graduates of universities must not only master subject knowledge and skills, but also be able to apply various methods of activity to solve professional problems. The last requirement is the basis of key competencies, which, according to Federal State Educational Standard of Higher Education, are formed while undergraduate students master university disciplines.

In order to develop a work program of discipline, the teacher must provide the organization of the undergraduate student activity in order to form the readiness to solve professional problems, be engaged in self-education, use information resources, communicate, including in the professional community. Note that the module of the basic or variable part a work program of discipline developed by a teacher has the great potential of content. Indeed, the module provides general cultural training, development of various mental activities (comparison, analysis, synthesis, etc.), ability to learn, universal ways of working and ability to use the ways to solve various problems, including professional ones associated with a practical block of discipline. The effectiveness a work program of discipline implementation is related to the use of pedagogical technologies by the teacher. There are the following two approaches to construct a cluster of pedagogical technologies.

1) The cluster includes pedagogical technologies, which are professional skills of the teacher and can be apply separately from each other. For example, a cluster system can combine technology of problem training, case technology, information and communication technology.

2) The cluster purposefully combines traditional and innovative pedagogical technologies. At the same time, a powerful resource is created in the form of Universality and Independence of motivations («UnInd of motivations»). This approach allows to unify the cluster system itself, because the combination of small number of pedagogical technologies allows to grade negative sides of the technologies, and, at the same time, to use clear and short wording.

We propose a cluster of pedagogical technologies (Fig. 1) that allows:

- activate thinking of the undegraduate students for an independent, creative and justified solution of the proposed problem situation;

- develop partnership relations (interaction of the form subject-subject);

- increase the effectiveness of training by depth and speed of creative processing information by means a SMART-technologies without increase in the volume of processed information contained in the case;

- ensure stable formation of educational and professional motivations for training, as well as competencies of undergraduate students. 


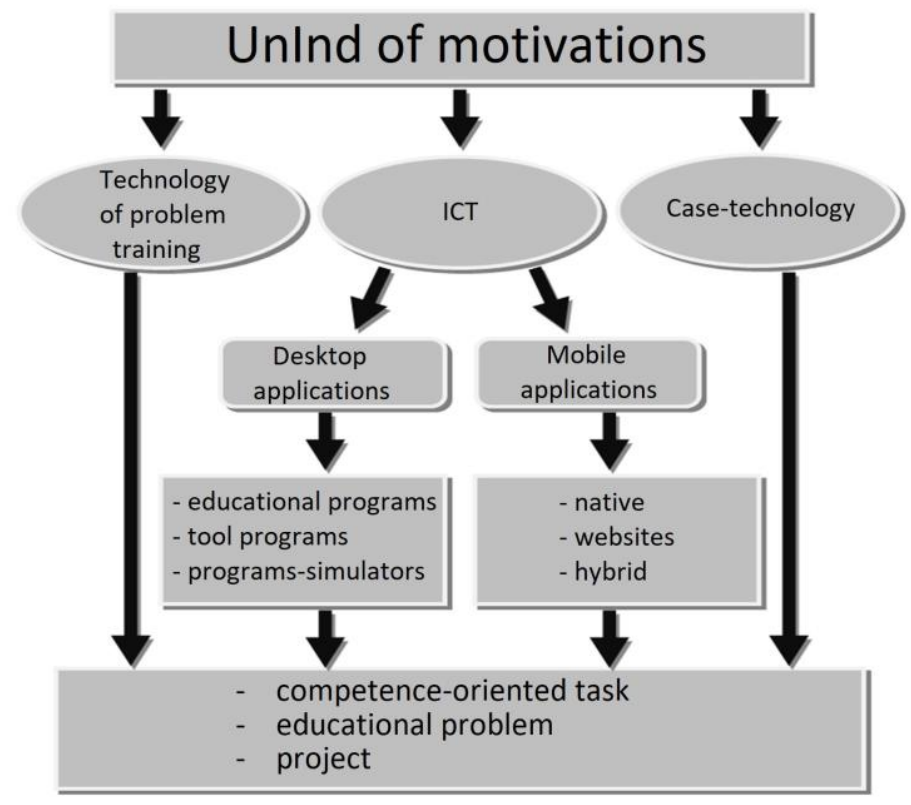

Fig. 1. Cluster of pedagogical technologies "UnInd of motivations".

"UnInd of motivations" is based on the following principles.

1. Together form professionalism here and now.

2. If you have solved your problem, then help your colleague to solve his or her problem.

3. SMART-technologies is the basis to extract and process educational and professional information.

The essence of the proposed cluster of pedagogical technologies is as follows.

- The aim is to form the educational and professional motivations of undergraduate students for cognitive and research activities.

- Training by means of work with the case is represented as a process of business communication in the form "student - student" and / or "student - teacher".

- Resolution of problem situations is transferred to the level of quasi-professional activity.

- The own "product" is created by means of SMART-technologies.

- Formation of the educational and professional motivation of undergraduate students is not limited only by the work during the lecture time, i.e. independent work beyond the lecture room is widely used.

The use of the proposed cluster of pedagogical technologies in the course "Physics of the Earth" allows to solve the following two problems provided by a work program of discipline. First, to form the competence - the ability to use knowledge about land resources in order to organize their rational use and determine activities to reduce anthropogenic impact on the territory. Second, to create conditions for the following goals.

- Undergraduate students master the topic "Application of geophysical methods to solve environmental problems", as well as skills to use desktop and mobile applications to master geophysical methods for solving environmental problems.

- Process by creative way a thematic material located on different media.

- Create "learning product" by means of various SMART-technologies tools.

- Demonstrate and protect a thematic project.

Let us consider some of ways to use the cluster of pedagogical technologies. The organizational basis of the training space is the adapted cascade model proposed by Winston Royce in 1970. According to the model, all stages of work on the project are implemented in 
the consistent or strictly fixed order.

There is the following order of phases to develop software product in the original Royce waterfall model [18].

1. Identification of requirements.

2. Designing.

3. Construction (also "implementation" or "coding").

4. Integration.

5. Testing and debugging (also "verification").

6. Installation.

7. Support.

We propose students to apply these phases in order to work with a case, which contains study problems, project topics, and competence-oriented tasks. The proposition is used to recreate a whole picture of the considered phenomenon on the topic "Application of geophysical methods to solve environmental problems" of course "Physics of the Earth", as well as to form professional motivation. The topic of the course is selected not only as an educational topic, but also as a variant of comprehension of the main tasks of the cluster of pedagogical technologies "UnInd innovations" (a kind of UnInds). During the work with the case materials on the considered topic, undergraduate students not only study theoretical basis of the topic, but also create their own "trial" product of the educational topic with "given properties".

At the first stage (Phase 1 according to W. Royce), a group of undergraduate students works in a computer class. The aim of the work at computers is to master the considered topic, as well as present structural blocks of the topic in general. The blocks are necessary to create student's own computer version of theoretical content of the topic and possible application of the content in future professional activities.

At the second stage (Phases 2, 3 and 4 according to W. Royce), undergraduate students develop a model construction of the material considered as the subject of study, and then create a didactic model of the topic "Application of geophysical methods to solve environmental problems". The didactic model consists of several blocks: theoretical, practical, control. To this end, undergraduate students use desktop and mobile applications. Note that undergraduate students have different levels of training and creative capabilities $[19 ; 20 ; 21]$. Therefore, the versions that students create for work on the topic and used ICT (desktop and mobile applications) allow to process the topic several times and at different levels of complexity. As a result, the essence of educational content of the considered topic is organized, the programs of training tools are written, a project of the system of each training block objectives is created.

At the third stage of the educational process (Phases 5, 6 and 7 according to W. Royce), undergraduate students exchange the obtained "product" with each other (report on the work with the case materials: solution to the educational problem, development of the project, performance of competence-oriented tasks). At the same time, the information presented on any medium can be provided with notes, and undergraduate students can comment the results after processing whole topic. The most successful version is taken as the "basis", and the student group chooses the student, which will present the final form of "training product" within two weeks. To this end, the student also uses the versions proposed by other students. Therefore, several successful versions are obtained, since several groups master the considered course. Then, all successful versions are processed, verified and programmed as educational topics in a computer form by a temporary creative team of students, which includes the most motivated students.

Therefore, several versions of developed case on the same topic can be obtained. In future, we obtain the so-called computer "universal training store", which can be used as a «store of creative products», where students can choose the entire case or some part of the case 
(educational problem, project, competence-oriented task) to process the topic material. The choice depends on the level of SMART-technologies and motivation to develop the main educational program.

Let us give an example. In order to master the topic "Application of geophysical methods for solving environmental problems", students consider this case containing tasks for the study of modern systems of technological integration of geophysical methods for solving environmental problems based on 15 Sustainable Development Goal: Protection and restoration of terrestrial ecosystems and promotion of their rational use, rational forest management, combating desertification, stopping and reversing the process of land degradation and stopping the process of biodiversity loss.

On the basis of the case, students perform the following tasks:

1) make a comparative assessment of desktop and mobile applications that expand the information capabilities of technological, ecological and geophysical complexes;

2) analyze the main remote aerospace geophysical methods of research, as well as equipment for geophysical research;

3) study belief about geophysical anomalies, basic concepts and problems of "geopathogenesis", using various sources of information.

In addition, as future specialists in the field of land management, undergraduate students need to have the following abilities:

1) justify the processes of changes in natural resources (including land resources) under the influence of human productive activities;

2) give examples of the implementation of rational and environmental nature management and environmental protection;

3) predict the consequences of professional activity from the point of view of geophysical regularities;

\subsection{Task}

1. Determine the problems of geophysical research methods and application of the methods in order to study environmental components and to solve a wide range of geoecological problems.

2. Characterize the existing opportunities for geophysical control and forecast of environmentally dangerous changes in the environment.

3. Classify and characterize the main sources of anthropogenic physical contamination, as well as transformations and migrations of the sources.

4. Identify methods of engineering environmental protection, as well as actions to reduce anthropogenic impact on the territory.

5. Substantiate the choice of SMART-technologies and the use of desktop and mobile applications in terms of the considered problem and resources, which are available to perform the task on applying geophysical methods in solving environmental problems.

6 . Submit a report on the performed work taking into account the identified requirements to the developed product.

The organization of student work on creation of "educational product" is schematically presented in fig. 2. In order to create the product, students use the cluster of pedagogical technologies "UnInd of motivations" and the cascade model proposed by U. Royce, which is adapted to the organization of student work with the case. At this example, we consider topic "Application of geophysical methods to solve environmental problems" of the course "Physics of the Earth". 


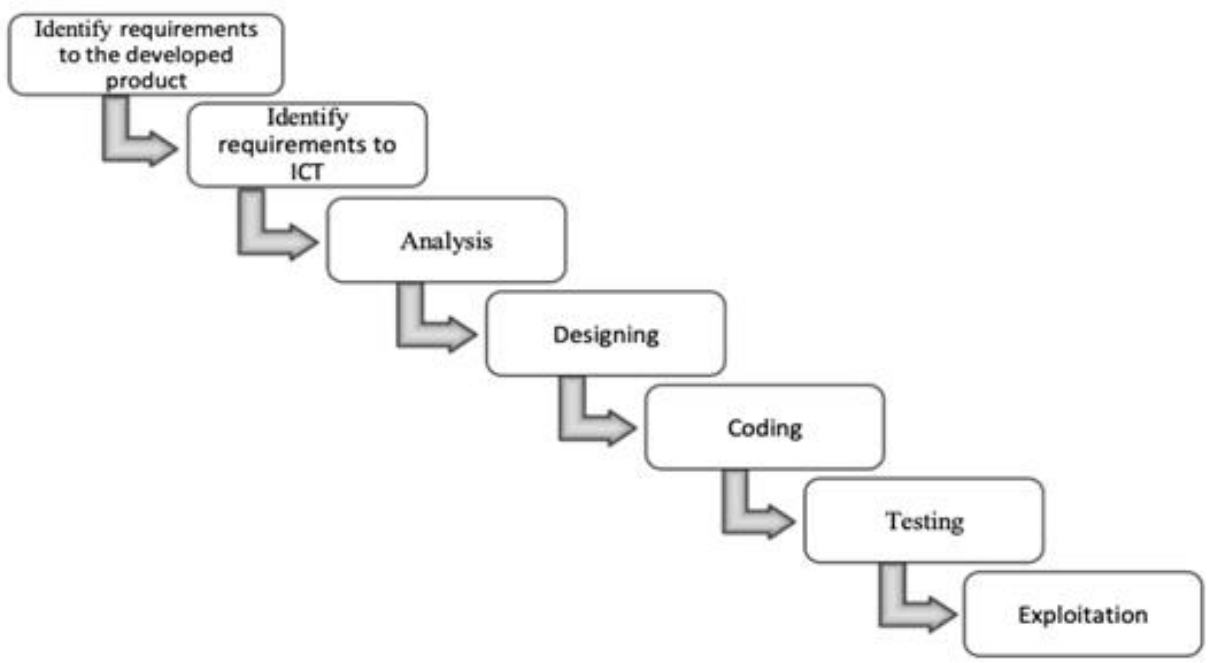

Fig. 2. Phases of the cascade model proposed by U. Royce and adapted to the organization of student work with a case.

Therefore, we developed the methodology based on a cluster of pedagogical technologies and the adapted cascade model proposed by W. Royce. The methodology was tested both for full-time and extramural forms of bachelor's training in the field "Land management and cadastres" within the study of the discipline "Physics of the Earth" for several years in the "South Ural University of Technology" in Chelyabinsk. In order to organize the educational process by means of the proposed methodology, we took into account the disadvantages of the cascade model and pedagogical technologies [22], which are included in the cluster "UnInd of motivations". The organization by means of the proposed methodology allows to form the educational and professional motivation of undergraduate students and to use effectively the time provided for independent work on the discipline beyond the lecture room. Note that this time achieves $90 \%$ in extramural forms of education.

\section{Results}

There are the following advantages of the organization of student independent auditor and extracurricular work to master the discipline "Physics of the Earth" by means of the cluster of pedagogical technologies and an adapted cascade model. First, students are motivated to study not one but several cases on the topic within one lesson. Second, students perform tasks having different levels of complexity. Third, students have the right to test their capabilities at any level. Finally, extramural students can use cases to study the course in the individual mode.

In order to organize the feedback from undergraduate students on their activities within the work with the case materials, we asked them the following questions posted in the Internet on the basis of the platform UNIT4 (Fig. 3). 
1. What kinds of work with the case materials are most significant for you in the professional plan?

$\square \quad$ work with theoretical material

$\square$ resolution of an educational problem

$\square \quad$ work with the project on the topic under study

$\square$ performance of competency-oriented task

$\square$ work in a temporary creative team

$\square \quad$ leadership of the temporary creative team

2. How interesting is the presented material for you personally?

$\square \quad$ very interesting

$\square$ not interesting, but necessary for further professional activity

$\square$ not interesting and not necessary for further professional activity

3. Have the goals and objectives of the lesson been achieved?

$\square$ yes

$\square$ no

4. What did you learn?

Fig. 3. Questions to students posted on the Internet based on the UNITY 4 platform.

In order to reveal changes in the formation of educational and professional motivation level of the full-time and extramural students, we diagnosed on the basis of the UNIT4 platform at the beginning and after the completion of the course "Physics of the Earth".

An analysis of the research results (Table 1) shows that the interrogated undergraduate students have different levels of educational and professional motivation. At the same time, the low level predominates at the beginning of the course, and the distribution of the number of students at low and high level changes after the completion of the course (Fig. 4).

Table 1. Results of feedback from full-time and extramural undergraduate students at the beginning and after the completion of the experiment (in \%).

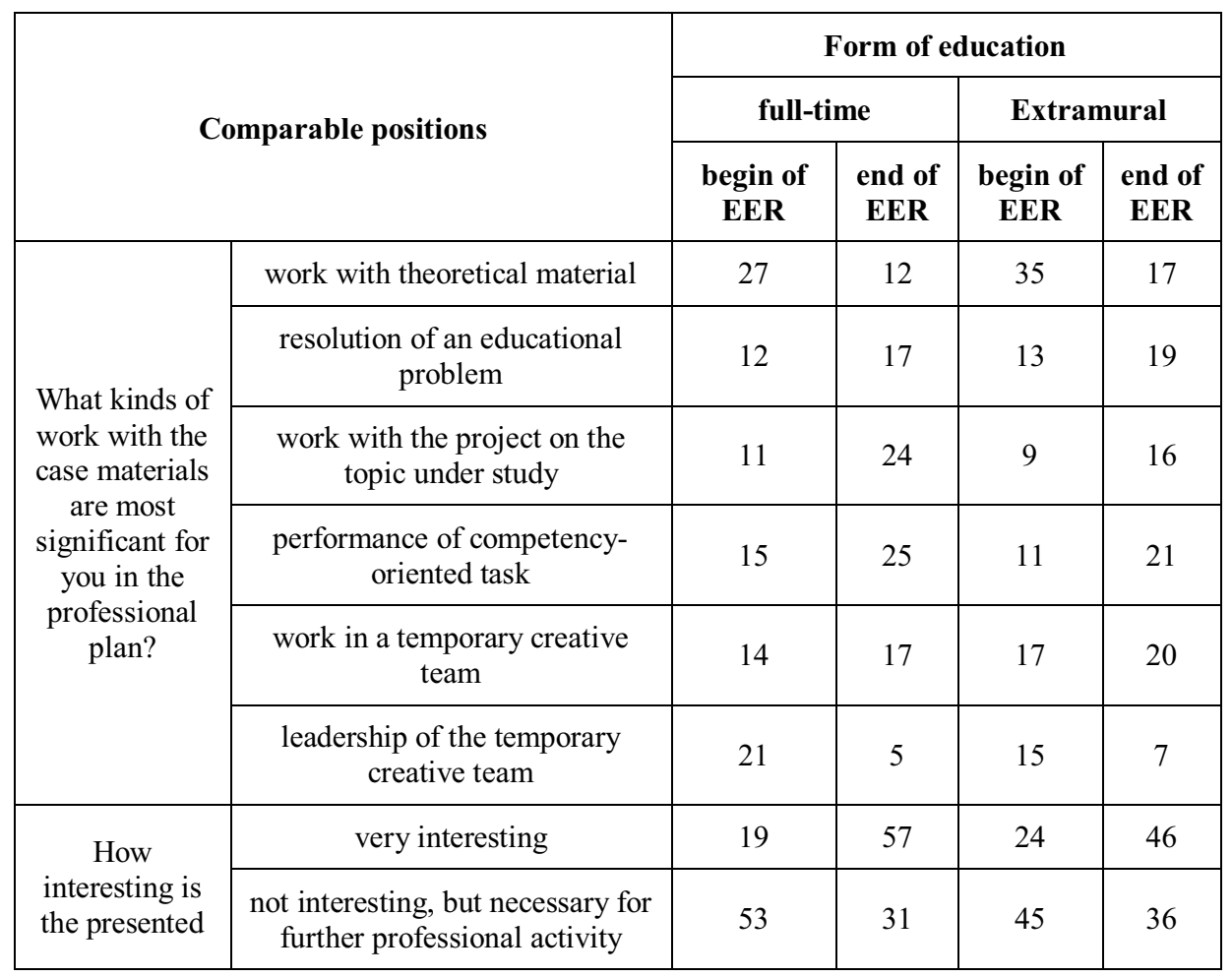




\begin{tabular}{|c|c|c|c|c|c|}
\hline $\begin{array}{c}\text { material for } \\
\text { you } \\
\text { personally? }\end{array}$ & $\begin{array}{c}\text { not interesting and not necessary } \\
\text { for further professional activity }\end{array}$ & 28 & 12 & 31 & 18 \\
\hline $\begin{array}{c}\text { Have the goals } \\
\text { and objectives } \\
\text { of the lesson } \\
\text { been } \\
\text { achieved? }\end{array}$ & yes & 53 & 87 & 57 & 83 \\
\cline { 2 - 6 } & no & 47 & 13 & 43 & 17 \\
\hline
\end{tabular}

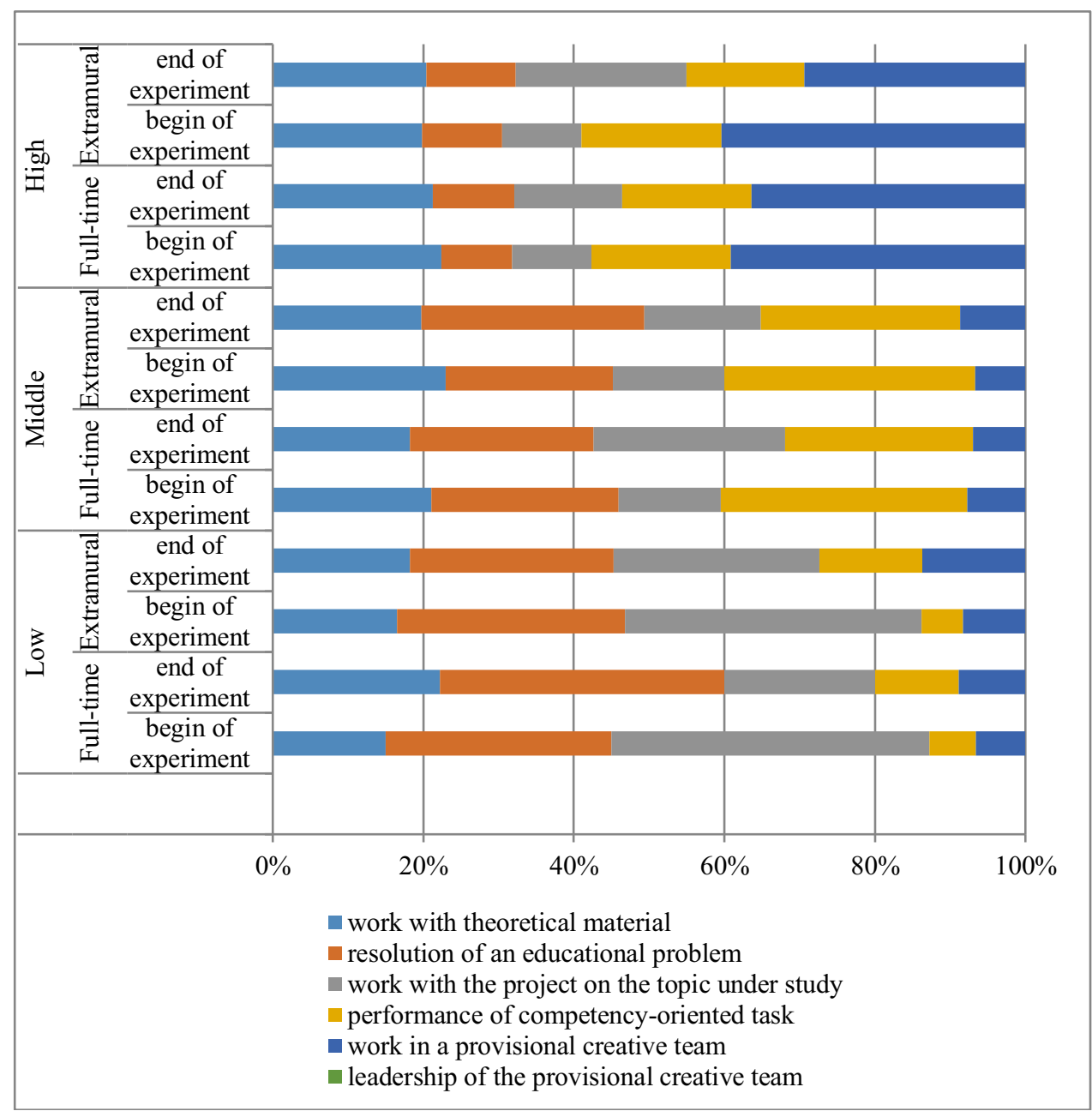

Fig. 4. Change in the distribution of educational and professional motivation levels of students.

\section{Conclusion}

Therefore, the cluster of pedagogical technologies "UnInd of motivations" has ample opportunities and allows to carry out the educational process in a new way in the modern conditions of the university. The creation of modern teaching technologies, as well as the modernization of already available ones on the basis of management theory, is an attempt to overcome the excessive traditionalism in creating conditions for the achievement of planned 
learning results. Requirements of the information society, socio-economic realities, transition to Federal State Educational Standard at all levels of education lead to a review of the entire education system. Namely, practical and personal orientations of education increases, as well as problems that traditionally inhibit are solved. One of the problems is absence of motivation to learn all life in order to develop personal potential and achieve high results in the professional sphere.

In the context of achieving the sustainable Development Goals, knowledge and skills of students of a certain level of training are just as important as the level of their motivation, readiness and ability to realize their or her opportunities at the subsequent stages of training or professional self-improvement.

\section{References}

1. World Economic Forum Documentary: The Fourch Industrial Revolution, https://www.youtube.com/watch?v=kpW9JcWxKq0

2. O. Shefer, L. Nosova, T. Lebedeva, Scientific and technical information. Series 1: Organization and methodology of information work 5, 6-12 (2018) DOI: $10.3103 / \mathrm{S} 0147688218020077$

3. Y. Dmitriyeva, S. Demtsura, T. Lebedeva, O. Shefer, V. Mikhailov, V. Mikhailova, S. Sannikova, Espacios 48(41) (2020) DOI: 10.48082/espacios-a20v41n48p02

4. M. Bogorodskaya, Industry 4.0: The situation on the labor market will change dramatically, http://www.up-pro.ru/library/opinion/industry40-rynok.html

5. V. Chemekov, Grading: technology to build a personnel management system (Vershina, Moscow, 2007)

6. M. Shnarbekova, Behind Educational and Society 60(4), 370-380 (2018) DOI: 10.1080/10609393

7. O. Shefer, S. Kraineva, Psychology of learning 12, 82-94 (2017)

8. K. Kiemer, A. Groschner, M. Kunter, T. Seidel, European Journal of Psychology of Education 33(2), 377-402 (2018)

9. S. Kraineva, O. Shefer, Scientific and Technical Information Processing 2(44), 94-98 (2016)

10. Watted, M. Barak, Internet and Higher Education 37, 1-20 (2018)

11. O. Hniedkova, Proceedings of the 14th International Conference on ICT in Education, Research and Industrial Applications. Integration, Harmonization and Knowledge Transfer II, 447-461 (2018) http://ceur-ws.org/Vol-2104/

12. O. Shefer, I. Bespal, S. Kraineva, Espacios, 40(29), 1-9 (2019)

13. S. Kraineva, Capital 2, 29-31 (2018)

14. S. Seliverstova, World Applied Sciences Journal 25(9), 1334-1338 (2013) DOI: 10.5829/idosi.wasj.2013.25.09.13408

15. S. Shashkova, Russian education and society 2(52), 19-36 (2010) DOI: $10.2753 /$ RES1060-9393520202

16. O. Shefer, T. Lebedeva, M. Goryunova, Espacios 52(39) (2018)

17. D. Sandler, A. Sushchenko, Economy of Region 2, 547-559 (2016) doi 10.15826/recon.2016.2.2.021

18. W. Winston, Proc. IEEE WESCON http://www.cs.umd.edu/class/spring2005/cmsc838p/Process/waterfall.pdf 
19. Free online library "United window to educational resources". Introduction to Software Engineering: A Training Course, http://window.edu.ru/catalog/pdf2txt/409/61409/31136?p_page=2.

20. G. Selevko, Encyclopedia of educational technologies (People's Education, Moscow, 2005)

21. L.A. Mierin, N.N. Bykova, E.V. Zarukina, Modern educational technologies in the university: teaching aid (Publishing house SPbSEU, SPb, 2015)

22. Traditional software development processes. Stages of software development. Waterfall and spiral processes, RUP, http://pandia.ru/text/77/255/57699.php 